\title{
Felid Herpesvirus Type 1 Infection in Cats: A Natural Host Model for Alphaherpesvirus Pathogenesis
}

\author{
Roger Maes \\ Departments of Pathobiology and Diagnostic Investigation and Microbiology and Molecular Genetics, \\ College of Veterinary Medicine, Michigan State University, East Lansing, MI 48824, USA \\ Correspondence should be addressed to Roger Maes, maes@dcpah.msu.edu
}

Received 11 September 2012; Accepted 20 October 2012

Academic Editors: M. H. Kogut, V. Nair, and S. Takai

Copyright ( $) 2012$ Roger Maes. This is an open access article distributed under the Creative Commons Attribution License, which permits unrestricted use, distribution, and reproduction in any medium, provided the original work is properly cited.

Feline herpesvirus 1 (FeHV-1) is an alphaherpesvirus that causes feline viral rhinotracheitis, an important viral disease of cats on a worldwide basis. Acute FeHV-1 infection is associated with both upper respiratory and ocular signs. Following the acute phase of the disease lifelong latency is established, primarily in sensory neuronal cells. As is the case with human herpes simplex viruses, latency reactivation can result in recrudescence, which can manifest itself in the form of serious ocular lesions. FeHV-1 infection in cats is a natural host model that is useful for the identification of viral virulence genes that play a role in replication at the mucosal portals of entry or are mediators of the establishment, maintenance, or reactivation of latency. It is also a model system for defining innate and adaptive immunity mechanisms and for immunization strategies that can lead to better protection against this and other alphaherpesvirus infections.

\section{Introduction}

Felid herpesvirus 1 (FeHV-1) is classified under the Order: Herpesvirales, Family: Herpesviridae, Subfamily: Alphaherpesvirinae, and genus: Varicellovirus [1]. Characteristics of the members of the Alphaherpesvirinae are their short replication cycle, induction of lifelong latency, primary in neurons, and, in most cases, a narrow host range. Both human and animal herpesviruses are members of the Alphaherpesvirinae subfamily. Human herpes simplex viruses types 1 (HSV-1) and 2 (HSV-2), respectively, cause cold sores and genital lesions. Varicella zoster virus (VZV) is the causative agent of chickenpox, and the reactivation of latent VZV DNA causes shingles. Some of the mammalian herpesviruses, besides FeHV-1, classified under this family include bovine herpesvirus-1 (BoHV-1), which causes respiratory disease and abortions in cattle, equine herpesvirus-1 (EHV-1), which causes respiratory disease, abortions, and in some cases neurological disease in horses, Suid herpesvirus 1, also known as pseudorabies (PRV) and Aujeszky's disease virus, leading to respiratory disease, abortions, neurological disease in swine, and canid herpesvirus-1 (CaHV-1), responsible for neonatal mortality in puppies and also respiratory and ocular disease in juvenile and mature dogs. Examples of avian alphaherpesviruses are infectious laryngotracheitis virus (ILTV), causing severe respiratory disease in poultry, and Marek's disease virus (MDV), which induces immunosuppression and T-cell lymphomas.

FeHV-1 infection causes feline viral rhinotracheitis (FVR), which not only accounts for approximately half of all diagnosed feline viral upper respiratory infections, but is also an important cause of ocular lesions in cats. As is the case for other alphaherpesvirus infections, the acute phase of FVR is followed by lifelong latency. During the latent stage, viral FeHV-1 DNA persists in episomal form, primarily in the nuclei of sensory ganglion neurons. The transcription of viral RNA is very limited, and infectious virus is not produced. The reversal of the latent state, induced by natural stressors or the administration of corticosteroids, can induce viral reactivation in latently infected cells, leading to renewed production of infectious virus. Reactivated infectious virus then travels to the periphery by anterograde axonal transport, potentially leads to clinical signs (recrudescence), and can lead to viral transmission [2-5]. 
Since FeHV-1 is a primary pathogen of cats, with respiratory and ocular disease components that are similar to those of human herpesviruses, and latency which is easily reactivated under natural conditions, FeHV-1 infection in cats is considered to be a good natural host model to study the comparative molecular pathogenesis of acute and latent alphaherpesvirus infections and to test novel immunization strategies.

\section{Virus Characteristics}

The size of FeHV-1 virions ranges from 120 to $180 \mathrm{~nm}$. They are composed of a core containing the double-stranded viral DNA genome, an icosahedral capsid surrounding the core, a tegument layer surrounding the capsid, and a lipid bilayer envelope from which glycoprotein spikes are protruding [6, 7].

FeHV-1 primarily infects domestic cats, but lions and cheetahs are also susceptible [3, 8]. In vitro, FeHV-1 replicates only in cells of feline origin. Alphaherpesviruses that are genetically related to FeHV-1 are canid herpesvirus 1 (CaHV1 ) and phocid herpesviruses(PhHV) 1 and 2 [3, 9-11].

\section{Genomic Organization}

Our laboratory [12] reported the first Sal I map of the genome of C-27 strain of FeHV-1 and determined that its size was approximately $134 \mathrm{~kb}$. Grail et al. [13] subsequently mapped the genome of the FeHV-1 B927 strain and determined that its genome was only $126 \mathrm{~kb}$ in size. The genomic organization of both of these FeHV-1 strains was found to be similar to that of other varicelloviruses. Basically, the FeHV1 genome consists of two segments of unique DNA, referred to as the Unique Long (UL) and Unique Short (US) regions. The US region of the genome is flanked by a pair of identical, but inverted sequences designated the Internal Repeat Short (IRS) and Terminal Repeat Short (TRS).

We recently reported the first complete genomic sequence of FeHV-1, as well as the construction and characterization of a BAC clone containing the entire viral genome. Complete genomic sequences were derived from both the FeHV-1 BAC and purified virion DNA. These data showed that the FeHV-1 genome is 135,797 bp in size and has a GC content of $45 \%$. A total of 78 open reading frames were predicted, encoding 74 distinct proteins. The gene arrangement was found to be colinear with that of most other varicelloviruses whose genomes have been sequenced [14].

All alphaherpesviruses are considered to have a replication pattern that is similar to the one of HSV-1 [6, 7]. FeHV1 has previously been shown to contain 23 virion-associated proteins [15]. Eight glycoproteins had initially been identified, designated as gB, gC, gD, gE, gG, gH, gI, and gL. The examination of the recently derived complete sequence showed that the FeHV-1 genome in fact contains a total of 13 envelope glycoproteins [14].

Most studies on the function of FeHV-1 genes have been focused on the role of envelope glycoproteins [16], because of their predicted role in inducing protective host immune responses and, therefore, their potential for vaccine development.

\section{Acute Infection}

FeHV-1 typically affects kittens and juvenile cats. Most kittens are protected by passive immunity until they are about 2 months of age.

The pathogenesis of FHV-1 is based upon two different mechanisms. The first is that FeHV-1 is a cytolytic virus. Examples of its cytolytic effects are ulcerations in mucosae and the cornea. The second mechanism is immune-mediated, clinically manifesting itself as stromal keratitis. An important question related to this second pathogenetic mechanism is the source of the antigenic stimulation driving this reaction [17].

The main sources of FeHV-1 transmission are oronasal and ocular secretions from acutely infected cats. Viral transmission can also be associated with the reactivation of latency. Kittens with residual passive immunity may not show clinical signs when exposed but become latently infected [18].

Following entry via the oronasal route, FeHV-1 replicates extensively in the mucosae of the upper respiratory tract and generally causes severe upper respiratory disease in susceptible animals. The incubation period varies from 2 to 6 days. The primary replication sites of FeHV-1 include the mucosae of the nasal septum, turbinate, nasopharynx, conjunctivae, and upper trachea. Replication also takes place in tonsils and mandibular lymph nodes.

Acute respiratory FeHV-1 infection is characterized initially by fever, inappetence, and sneezing, followed by serous nasal discharge, which can become mucopurulent after 57 days. In addition, oral replication of the virus can result in excessive salivation and drooling of saliva. Occasionally coughing and dyspnea may occur. Oral ulceration, a typical feature of feline calicivirus infection, may occur as a result of FeHV-1 infection of the oral cavity but is uncommon [3].

The ocular manifestations associated with FeHV-1 infection have been reviewed by Gould [5]. In neonatal kittens ophthalmia neonatorum has been described and can lead to serious corneal damage. Acute hyperemic conjunctivitis, leading to ocular discharge and chemosis, a feature of acute infection, occurs in association with upper respiratory signs. The formation of branched epithelial ulcers, referred to as dendritic ulceration, is a pathognomonic feature of acute ocular FeHV-1 infection. In a recent review of the etiology corneal ulcers in cats, Hartley [19] stated "assume FHV-1 unless proven otherwise.” Occasionally, larger ulcers, referred to as geographic corneal ulcers, develop. Both dendritic and geographic corneal ulceration may also result from latency reactivation. Another component of lesions associated with recrudescence is conjunctival and/or corneal inflammation, which is milder than seen during acute disease.

FeHV-1 is primarily an upper respiratory and ocular pathogen, with only sporadic involvement of the lungs. Viremia levels are low, thought to be related to the natural temperature sensitivity of this virus, which would favor 
replication in the upper respiratory tract. Exposure of pregnant queens can lead to abortion, but infection with FeHV-1 infection is not a common cause of abortion in cats. In neonatal kittens, the infection can generalize and is associated with neurological signs and a high mortality rate.

\section{Alphaherpesvirus Latency Concepts}

A hallmark of alphaherpesvirus biology is that acute infection is followed by lifelong persistence of the viral genome in latent form in nervous and lymphoid tissues. Latency and periodic reactivation of latency are integral parts of the lifecycle of alphaherpesviruses and important elements in their survival and transmission.

The latency-reactivation cycle operationally consists of three major steps: establishment, maintenance, and reactivation.

The establishment of latency by definition requires that the virus reaches the tissue in which latency will be established. This process starts during the acute phase of viral replication at peripheral mucosal sites. Nerve endings of sensory nerves innervating viral replication sites take up viral particles and subparticles during this phase. These particles are transported within the axoplasm of the axons of these nerves by a process referred to as retrograde axonal transport. When the virus reaches the sensory ganglia, it infects neurons and other cell types. This acute infection of ganglionic cell types lasts for approximately one week. Neurons are the cell type in which latency is established. In order to accomplish this, lytic gene expression is repressed, while the latencyassociated transcript (LAT) is expressed, which yields several RNA species by splicing. These multiple species are collectively referred to as LATs. Low level or sporadic transcription of immediate-early and early genes can occur but is not sufficient to initiate a productive infection. No infectious virions can be detected in the ganglia during latent infection. The LAT RNA is spliced, and a stable intron in the form of a lariat, called the 2-kb LAT, is produced in the nucleus. The spliced LAT mRNA is transported to the cytoplasm, where several small ORFs may be translated into proteins.

During the maintenance phase of latency, the viral DNA is present in the neurons in an episomal form. The viral DNA is not totally static during the maintenance phase of latency, but transcriptional activity of the genome is limited to a region referred to as the latency-associated transcript or LAT.

The maintenance phase of latency is reversible. In other words, under the influence of certain natural or pharmacological stimuli, the reactivation of latent viral DNA can occur. Virus replication starts up again, and infectious virions then travel back to the periphery, using the same sensory nerve "highway" used to reach the ganglia. Infectious virus can be detected again by virus isolation or PCR from nasal, oral, or ocular swabs. Usually the clinical signs associated with the reactivation process are significantly milder than those seen during the primary infection, and reactivation can certainly be asymptomatic. Virus shedding resulting from reactivation is also typically at a lower level and of shorter duration than seen during primary infection. However, reactivating virus can still be a significant source of exposure and primary disease in fully susceptible hosts that are in close contact with the animal in which reactivation took place. Reactivation occurs in only a small subset of latently infected neurons, typically less than $0.05 \%$. Latently infected neurons in which reactivation took place do not survive. This explains why sensory deficits are not associated with reactivation in sensory nerve ganglia. Since the reservoir of latently infected neurons remains large under these conditions, repeated reactivation can take place throughout the life of the host.

Our current understanding of the regulation of latency is derived primarily from studies on HSV-1 and BoHV-1 [2022]. The following summary is derived primarily from an excellent very recent review of HSV-1 latency by Perng and Jones [20].

5.1. The Role of Latency-Associated Transcripts (LATs). Acute infection of trigeminal ganglia neurons produces toxic gene expression products that make them vulnerable to damage and death. In addition, cellular DNA damage induced by viral replication stimulates the mitochondrial pathway of apoptosis. Herpesviruses try to counteract apoptosis and thus enhance their replicative ability, by encoding several antiapoptotic genes, one of which is the LAT gene. Since there is redundancy in the viral antiapoptotic capabilities during the acute phase, apoptosis of neurons during this phase is prevented fairly efficiently.

It is very important that apoptosis is prevented also during the establishment and maintenance stage of latency. This is especially crucial in permissive neurons, in which extensive viral replication has taken place during the acute phase. LAT exerts its antiapoptotic properties through micro-RNAs (miRNAs). A mechanism by which LAT-encoded miRNA regulates apoptosis is targeting of transforming growth factor beta, a potent inducer of apoptosis [23, 24].

It is important to understand the interactions between the latent viral genome and the neuron that lead to reactivation, because this is a prerequisite to ultimately controlling this process. LAT plays an important role in the in vivo reactivation of latency. In experimental studies it has been shown that spontaneous reactivation is severely impaired if the LAT gene is deleted.

5.2. The Role of Tegument Protein VP16. Thompson et al. [25] have recently described the central role played by the tegument protein VP16 in all phases of HSV latency. Prior to establishment of latency virus replication takes place in permissive neurons. In susceptible cells at mucosal surfaces VP16, a component of virions entering the cell, combined with cellular factors, activates the immediate early genes. Axonal transport of VP16 into neurons is inefficient, which would promote latency. In order for VP16 to initiate lytic infection, it needs to be synthesized de novo, a process which requires that neuronal inhibition be overcome.

Very interestingly, the LAT locus is considered to express riboregulators that mediate synthesis of VP16. It has been shown that, in the absence of LAT transcription, half of 
the neurons destined to be latently infected instead enter the lytic cycle and die. In contrast when repression is overcome, neurons become lytically infected, and the infectious virus produced spreads both within the ganglia and back to the mucosal surface where infection was initiated. The goal of lytic infection is to increase the number of latently infected cells.

Stress, leading to reactivation, is hypothesized to increase the novo production of VP16 by a mechanism that is still under investigation. The VP16 produced then initiates a feedback loop with the IE genes and results in viral reactivation in a very limited number of latently infected neurons.

5.3. The Role of Local Cell-Mediated Immune Responses. T cells, especially CD8+ T lymphocytes, have been found to be crucial for acute controlling HSV infection in sensory ganglia. Viral antigen production in trigeminal ganglia increases until 3 days after infection but is no longer detectable at 7 days after infection. As antigen production decreases, there is an increase of different types of different types of lymphoid cells, such as macrophages, natural killer cells (NK), and certain CD8+ T cells surrounding infected neurons.

It is thought that T cells, especially CD8+ T lymphocytes, inhibit reactivation from latency. Persistence of immune effector cells in trigeminal ganglia (TG) implies that low levels of viral proteins are expressed and that an immune response occurs. In a mouse HSV-1 model, it has been demonstrated that viral DNA replication, transcription, and viral protein production take place in 1 neuron per $10 \mathrm{TG}$. These individual neurons are considered to be undergoing "spontaneous molecular reactivation" and are consistently surrounded by cuffs of infiltrating white blood cells. Two mechanisms by which these infiltrating cells prevent reactivation are the production of gamma interferon and lymphocyte-mediated cytotoxicity.

\section{Reactivation of Latency}

The trigeminal ganglion is considered a primary site of latency for FeHV-1 although recent studies implied other tissues as potential sites $[26,27]$.

Spontaneous reactivation is possible but does not occur frequently. More commonly leading to the reactivation of latent FeHV-1 is the result of environmental or physiological stresses, such as changes in housing or lactation. The reactivation frequency rates have been reported to be $18 \%$ as a result of moving cats to a new environment and $40 \%$ as a result of lactation [28-30]. The lag phase between the stressor leading to reactivation and the actual shedding of infectious virus is about 4-11 days, and virus excretion lasts for approximately 6 days on average. Virus excretion by cats in which a reactivation event took place ranges from 1-13 days $[29,31]$. During this time infectious virus can be demonstrated in ocular and oronasal secretions. The reactivation can be either asymptomatic or associated with clinical signs. Symptomatic reactivation is referred to as recrudescence. Reactivation of latent viral DNA in adult cats can lead to corneal ulceration, accompanied by varying degrees of conjunctivitis [32]. Since herpetic stromal keratitis caused by HSV-1 is the leading cause of infectious blindness in industrialized countries, ocular infection of FeHV-1 in cats is considered a very good natural host model.

The administration of corticosteroids has been reported to lead to reactivation in $70 \%$ of the latently infected cats [3]. Infectious virus is carried by anterograde axonal transport to peripheral tissues, usually to cells at or near the site of initial infection, and is a potential source of viral transmission [6, 7].

The role of reactivation in the epidemiology of alphaherpesviruses is directly related to the frequency by which it takes place. Some herpesviruses, including FeHV-1, reactivate much more easily than others from the latent state, both under natural and experimental conditions. The ease by which latent FeHV-1 DNA is reactivated is an important element in the justification of FeHV-1 infection of cats as a natural host model to study the molecular pathogenesis of herpesvirus latency and approaches to prevent it.

\section{Diagnosis}

Clinically, there is an overlap between the symptomatology of acute FeHV-1 and feline calicivirus (FCV), another major respiratory disease of cats. Distinguishing features of FeHV-1 infection are high fever and corneal ulcerations. In contrast, ulcers of the tongue, palate, and pharynx are more typical or encountered more frequently in calicivirus infections.

The most common laboratory diagnostic methods to demonstrate the presence of FeHV-1 or viral components in tissue homogenates or swabs include the direct fluorescent antibody (FA) test, virus isolation (VI), and PCR $[3,5,18]$.

Fluorescent antibody testing is performed on conjunctival or corneal tissue. This test is far less commonly used now than it used to be. Topical fluorescein, used to visualize ulcers, should be avoided prior to collecting samples.

Laboratory diagnosis of acute FeHV-1 is now most commonly performed by virus isolation (VI) or PCR, using oronasal and conjunctival swab extracts as the samples. VI detects infectious virus and has been the laboratory diagnostic gold standard $[4,28]$.

Multiple PCR assays have been described for use in the detection of FeHV-1 DNA. An excellent TaqMan-based realtime PCR assay, described by Vögtlin et al. [33], targets a conserved portion of the FeHV-1 gB gene. The assay was determined to be very specific for FeHV-1, and its detection limit was between 0.6 and $6 \mathrm{TCID}_{50}$. Infectious virus titers and viral DNA correlated over a wide dilution range. The real-time PCR (qPCR) was evaluated on sequentially collected ocular fluid extracts. Early during infection, referred to as phase 1 , the correlation between virus titers and qPCR signals was very high. Next, during so called phase 2 , a rapid decline in infectious virus titers was seen, while the qPCR signals remained high. During the final phase, referred to as phase 3 , infectious virus was no longer detectable, and the quantitative PCR signals were also declining. Analysis of the combined virus detection and qPCR results on 20 clinical samples allowed the authors to reliably define the phase of 
the infection during which the samples had been collected. Realizing the cost of combined testing, it was suggested to test consecutive samples by qPCR to accomplish this goal.

Maggs [4] pointed out 3 aspects of laboratory diagnosis of FeHV-1 that can be very frustrating for the clinician. Whereas the confirmation of acute FeHV-1 is not always required, it is important to confirm that chronic lesions are caused by FeHV-1. Unfortunately, the detection of FeHV-1 or viral components in these lesions can be difficult. The second aspect of laboratory diagnosis that leads to misinterpretations is the fact that FEHV-1 or viral 1 DNA can be detected in samples from clinically normal cats. It was pointed out that the detection of FeHV-1 or its components can be coincidental, consequential, or causal. Differentiating between these possibilities is obviously important.

Virus neutralizing antibody titers are determined by VN tests, which are commonly used to detect prior infection or the efficacy of vaccination. Virus neutralizing antibodies can be low and slow to develop. As pointed out by Dawson et al. [34], a low level of neutralizing antibodies does not imply the absence of protection against clinical disease.

\section{Treatment and Control}

8.1. Supportive Treatment. Guidelines for the management of FeHV-1-induced disease have been published by The European Advisory Board on Cat Diseases (ABCD) [18]. As is the case for many viral infections, supportive therapy is being advised. Broad spectrum antibiotics that achieve good penetration into the respiratory tract should be administered in all acute cases to prevent secondary bacterial infections. Intake of food that is palatable and flavorful is also important, since infected cats develop anorexia from the loss of their sense of smell or, less commonly, the presence of ulcers in the oral cavity. In cats with severe clinical signs, the restoration of fluids, electrolytes, and acid-base balance is required, preferably intravenously. Nasal decongestants, mucolytic drugs, and nebulization with saline can all ameliorate clinical signs. Eye drops or ointments, when used, should be administered several times a day.

8.2. Antiviral Therapy. Antiviral therapy consists of topically or systemically administered antivirals or the use of adjunctive therapies. Comparison of 8 antiviral drugs administered topically demonstrated that the highest efficacy was obtained with trifluridine, based upon its potency and corneal penetration. Second in effectiveness was idoxuridine, which has a lower cost and appears to be less irritating [4].

Nucleoside analogue antivirals are commonly used to treat HSV and VZV infections. They are converted into triphosphates by viral thymidine kinase and other host enzymes in infected cells and competitively inhibit viral DNA polymerase. This prevents DNA chain elongation [35] and, as a result, disrupts viral replication.

The use of these agents against FeHV-1 infection has been largely limited to topical administration. First generation nucleoside analogues, including acyclovir and its prodrug valacyclovir, have little efficacy against FeHV-1 in vitro and moderate effect in vivo. More importantly, when administered systemically they produce serious side effects in cats, including myelosuppression, hepatotoxicity, and nephrotoxicity at therapeutic levels [36, 37].

According to the guidelines of the European Advisory Board for Cat Diseases (ABCD), trifluridine is the topical treatment of choice in cats with ocular FHV-1 manifestations. Acyclovir, ganciclovir, and idoxuridine are also suggested for topical use. It was noted that, except for acyclovir, there is a lack of controlled in vivo efficacy study for these agents in the literature [18]. The efficacy of topical application of cidofovir on primary ocular FeHV-1 infection has been demonstrated [38].

Although the study wasn't controlled, oral administration of famciclovir has been reported to be safe and efficacious in treating ocular signs, cutaneous disease, and rhinosinusitis induced by FeHV-1 infection [39].

Adjunctive therapies that are used to treat FeHV-1 infection are L-lysine, lactoferrin, and interferons. L-lysine is an antagonist of arginine; the latter has been shown to be essential for HSV-1 and FeHV-1 protein synthesis [40]. Treatment with L-lysine, therefore, decreases viral replication and has been shown to have some inhibitory effect against both human herpesvirus and FeHV-1 infection. An issue with low dietary arginine concentrations is the pronounced susceptibility of cats to arginine deficiency [40, 42].

Oral supplementation with L-lysine reduces the severity of experimentally induced FeHV-1 conjunctivitis [42] and ocular virus shedding associated with the reactivation of latent infection [40]. It was suggested for use early in acute disease or as a means of reducing the severity of disease and virus shedding at times of stress [3]. It has been demonstrated that L-Lysine is safe at relatively high oral dose levels.

Lactoferrin is a mammalian iron-binding glycoprotein. It has been shown [43] to inhibit FeHV-1 replication in vitro, potentially as a result of interfering with the binding of FeHV-1 binding to its cellular receptor and/or viral penetration into susceptible cells.

Interferons are cytokines released by white blood cells and interfere with viral cell-to cell spread. Interferon-alpha (IFN- $\alpha$ ) administration has been shown to decrease clinical signs associated with acute infection [3].

\section{Immunity and Vaccination}

Primary FeHV-1 infection induces both humoral and cellular immune responses. Active immunity induced by natural FeHV-1 infection or immunization protects cats from the disease, but not from infection. Mild clinical signs have been observed upon reexposure as soon as 150 days after the primary infection $[18,44,45]$. Virus neutralizing antibody titers are generally low and in some cases undetectable after primary infection; although after further exposure to virus, they tend to rise to more moderate levels and thereafter remain reasonably stable $[3,46]$. Since FeHV-1 targets the eye and upper respiratory tract, mucosal immune responses also play a significant role [47]. 
Passive immunity persists for 2 to 10 weeks, depending upon colostrum concentration and intake. Some kittens with low levels of maternally derived antibodies that are exposed to field virus may develop subclinical infection and latency [48]. Alternatively, such kittens would also respond to early vaccination. Conversely, in some kittens maternally derived antibodies are high enough to still be at interfering levels at 12-14 weeks of age [3, 49].

Vaccination recommendations have been provided by The European Advisory Board for Cat Diseases (ABCD) and The American Association of Feline Practitioners Feline Vaccine Advisory Panel.

The ABCD panel recommends an initial two-dose vaccination regimen: the first dose being given at 9 weeks of age and the second at 12 weeks of age. This is followed by yearly boosters [18].

The American Association of Feline Practitioners Feline Vaccine Advisory Panel advises that the primary immunization dose should be given as early as 6 weeks of age, with additional doses every 3 to 4 weeks until 16 weeks of age. A booster dose is to be administered 1 year following the last dose of the primary series. Subsequent booster doses are then administered every $1-3$ years [50].

All current commercial vaccines against FVR also contain feline calicivirus (FCV) and feline panleukopenia virus (FPV) components and are collectively termed FVRCP vaccines. The protection induced by these trivalent vaccines is generally the lowest against the FeHV-1 component [51, 52].

Both modified-live and inactivated FVRCP vaccines for systemic use are available in the United States [50, 53]. Modified-live vaccines (MLVs) are routinely used, but they have residual virulence and may induce clinical signs if administered incorrectly [54]. Because of safety concerns, inactivated vaccines are mostly preferred for use in pregnant queens, and in cats that are infected with feline leukemia virus (FeLV) or feline immunodeficiency virus (FIV) [50].

In addition to vaccines labeled for systemic immunization, an intranasal multivalent vaccine containing a FeHV-1 component is commercially available. Testing under experimental conditions showed that this vaccine was safe and induced protection against the clinical signs of field virus exposure within a week after vaccination [53], versus 2-3 weeks with a systemically administered vaccine [55].

\section{New Approaches to Immunization}

10.1. Virulence Genes and Deletion Mutant Vaccines. As discussed earlier, currently available vaccines cannot totally protect cats from field virus infection and, as a consequence, from field virus latency [56-60].

A better understanding of herpesvirus virulence factors is a prerequisite for the generation of safe and efficacious deletion mutant vaccines. Candidate genes for deletion are those encoding the nonessential glycoproteins $\mathrm{gC}, \mathrm{gE}$, and gG, the US3 gene encoding a protein kinase, the UL 23, gene encoding thymidine kinase. The combination of BAC cloning of herpesvirus genomes and the introduction of recombineering to rapidly generate mutants within alphaherpesviruses cloned as BACs have been very useful tools to generate mutants with vaccine potential.

Glycoprotein E (gE) is a virulence factor of FeHV-1. Glycoprotein E (gE) and glycoprotein I (gI) form a heterodimer that functions in virus cell-to-cell spread of the virus and transsynaptic spread of infection throughout the host nervous system, an important component of neurovirulence. gE/gI are nonessential glycoproteins, except for MDV [61]. As an in vitro indicator of reduced virulence, gE/gI mutants have a smaller plaque size and reduced capacity for cell-to-cell spread [62-66]. A functional gE/gI heterodimer appears to play an even greater role in the spread of VZV [67-69].

We previously constructed a gE/gI deletion mutant by conventional in vivo recombination and reported that cats vaccinated subcutaneously with high doses of the recombinant FeHV-1 strain responded with only mild clinical signs and developed strong immunity against subsequent virulent virus challenge [70]. We also compared the intranasal and subcutaneous routes of administration of this strain and assessed its ability to induce protective immunity and prevent virus shedding after challenge. The only concern we had is that this mutant had some residual virulence when administered intranasally at high dosage levels [54].

Kaashoek et al. [71] constructed gE-, TK-, and gE-TKdeletion mutants of BoHV-1 and examined their virulence and immunogenicity in calves. After intranasal inoculation, the TK mutant showed some residual virulence, whereas the gE and gE-TK mutants were completely avirulent. The calves inoculated with these deletion mutants were protected against clinical disease after challenge exposure and shed significantly less challenge virus than control calves.

Recently, an EHV-1 gE mutant was evaluated as a modified live virus (MLV) vaccine. Colostrum-deprived foals inoculated intranasally (IN) or intramuscularly (IM) with the gE mutant did not exhibit any clinical signs of respiratory disease except for mild nasal discharge in one of the IN inoculated foals on Days 1 and 3 after infection. In contrast, foals inoculated IN with the revertant had biphasic fever, mucopurulent nasal discharge, and submandibular lymph node swelling. The efficacy of the gE mutant against wild type EHV-1 challenge infection was assessed using foals previously vaccinated twice IM with $10^{5}$ or $10^{6}$ plaque-forming units (pfu) of the gE-mutant at an interval of 3 weeks. These foals exhibited no respiratory disease signs after IM immunization and developed a good virus neutralizing antibody response to EHV-1 after the second dose. Following a wildtype EHV-1 challenge infection, vaccinated foals showed milder clinical symptoms than foals vaccinated with a placebo, and challenge virus shedding was significantly reduced [72].

The thymidine kinase (TK) gene of alphaherpesviruses is a virulence factor. Comparisons of the amino acid sequences of herpesvirus TK proteins showed that these proteins are highly divergent, sharing only short regions of imperfect amino acid identity. Nunberg et al. [73] first identified the TK gene of FeHV-1 using PCR with highly degenerate oligonucleotide primers. Yokoyama et al. [74] inserted the gene 
encoding the feline calicivirus capsid protein into the TK locus of FHV-1 and designated the recombinant C730ldfTKCap. In a pilot study, 2 cats were inoculated intranasally and orally with C730ldfTK-Cap, and one cat was inoculated via the same routes with C730ldfTK. Virus-neutralizing (VN) antibody against both FeHV-1 and FCV was induced with C730ldfTK-Cap, and against FeHV-1 with C730ldfTK.

The US3 gene of FeHV-1 encodes a serine/threonine protein kinase $(\mathrm{PK})$, and its amino acid sequence is conserved in the subfamily Alphaherpesvirinae [75-77]. Possible functions of PK include blocking of apoptosis induced by both viral and cellular proteins [78-81], regulation of the nuclear egress of progeny nucleocapsids $[82,83]$, and control of the morphology of infected cells [84, 85]. Kimman et al. [86] demonstrated that a PK-mutant of pseudorabies virus (PRV) has strongly reduced virulence, and animals inoculated with PK-gE-PRV mutant and subsequently challenged with wildtype virus has reduced virus shedding.

Glycoprotein C (gC) homologues have been extensively studied in several alphaherpesviruses. gC homologues are nonessential for herpesvirus replication in vitro, but they mediate several important biological functions. First of all, $\mathrm{gC}$ is involved in the initial step of viral attachment by interacting with heparan sulfate on cell surface, as demonstrated in HSV-1, PRV, BHV-1, and EHV-1 [87-90]. gC deficient mutants attach to cells with reduced efficiency [90]. Secondly, gCs of HSV-1 and -2 can bind the complement component C3b $[91,92]$. Binding of this complement factor may protect herpesvirus-infected cells from complementmediated lysis [93]. Viruses lacking complement-binding domains are less virulent than wild-type virus [87, 91, 92]. The $\mathrm{gC}$ of FeHV-1 has been shown to be the dominant heparin-binding glycoprotein that mediates the initial stage of viral adsorption, as observed in other herpesviruses [94]. However, it remains to be determined whether FeHV-1 gC protects virus-infected cells from complement-mediated lysis.

Willemse et al. [95] first determined a partial sequence of gC. They also found that the adjacent UL45 gene can be cotranscribed with gC. The complete sequence of FeHV-1 gC was later determined by Maeda et al. [96]. Based on the amino acid sequence deduced from the nucleotide sequence, they predicted that $\mathrm{gC}$ is a membrane glycoprotein containing a characteristic $\mathrm{N}$-terminal hydrophobic signal sequence, nine potential $\mathrm{N}$-linked glycosylation sites, and C-terminal transmembrane and cytoplasmic domains. Maeda et al. [97] further demonstrated that $\mathrm{gC}$ is the major heparin-binding glycoprotein involved in the initial step in virus adsorption to cells as observed in gCs of other herpesviruses. In addition, they found that gC can agglutinate murine red blood cells, and that infection of FeHV-1 is inhibited by the addition of soluble heparin in cells cultures.

The gG glycoprotein of herpesviruses interacts with chemokines, which are involved in the regulation of leukocyte trafficking and function and the regulation of inflammation and immunosurveillance. The gG glycoprotein of alphaherpesviruses can exist in three different forms: membranebound full length, membrane bound truncated or secreted. The full length form, present in FeHV-1 and EHV-1, can also exist as a truncated secreted form. The secreted form functions as a viral chemokine-binding protein (vCKBP) and is now classified under the vCKBP-4 subfamily [98].

Van de Walle et al. [99] used EHV-1 as a model to provide the first molecular determination of the residues in $\mathrm{gG}$ of EHV-1 involved in chemokine binding and interaction with target cells. In a very recent study, Thormann et al. [100] constructed recombinant viruses to show that the ability of the $\mathrm{gG}$ of EHV-1 to interfere with chemokine is not entirely mediated by its chemokine- binding region.

The gG of FeHV-1 exists in booth membrane-bound and secreted forms. The secreted form shows in vitro binding to bind to a number of chemokines. The membrane bound displays true viroreceptor characteristics [101].

Virulence characteristics of the gG of several alphaherpesviruses have been investigated. It has been shown previously that the deletion of gG in PRV does not have a significant effect on viral virulence [102]. In contrast, the administration of a gG-deleted ILTV to birds, the natural host of this virus, showed that the gG deletion resulted in significant reduction in virulence. Importantly, virulence could be restored with a revertant, and the transcription of genes adjacent to the gG deletion was not affected by the gG deletion. Immunization with the gG deletion mutant was shown to be protective against virulent virus challenge in experimental birds [103-105].

Herpesviruses have multiple immune evasion genes with various evasion mechanisms.

UL49.5 is a gene present in the genome of several members of the varicellovirus genus, such as EHV-1, BoHV-1, and PRV. UL49.5 inhibits transporter associated with antigen processing (TAP) and downregulates cell-surface expression of major histocompatibility complex (MHC) class I molecules [106].

A BoHV-1 UL49.5 null mutant was shown to no longer have the TAP inhibition and MHC-I downregulation properties of the parent virus [107]. In a follow-up study, the pathogenicity and immune responses in calves infected with BoHV-1 UL49.5 null mutant and the parent wild type strain were compared. Both strains replicated similarly in the nasal epithelium, and both groups had similar clinical scores. BoHV-1 antigen-specific CD8+ T-cell proliferation as well as CD8+ T-cell cytotoxicity in calves infected with the BoHV-1 UL49.5 null mutant peaked by 7 days after infection, 1 week earlier than in calves infected with the wild type strain. In addition, virus neutralizing antibody (VN) titers and IFN$\gamma$-producing peripheral blood mononuclear cells (PBMCs) in the UL49.5 mutant virus-infected calves also peaked 7 days and 14 days earlier, respectively. This study indicated that while immune responses peak earlier, deleting UL49.5 by itself did not sufficiently attenuate this alphaherpesvirus to make it a vaccine candidate [108].

10.2. Generating Mutants by BAC Clone Recombineering. BAC cloning and recombineering are two state-of-the-art techniques to facilitate the process of mutagenesis. BACs are single copy F-factor-based plasmid vectors, which can stably hold $300 \mathrm{~kb}$ or more of foreign DNA [109]. The BACs' larger 
capacity and greater stability over the other vectors have enabled the cloning of an entire herpesvirus genome into a single plasmid. These properties have also made BAC the vector of choice for the cloning of herpesvirus genomes.

Recombineering is a powerful method for fast and efficient manipulation of the BAC. It allows DNA cloned in $E$. coli to be modified via lambda $(\lambda)$ red-mediated homologous recombination, obviating the need for restriction enzymes and DNA ligases. Specific bacterial strains, for example, E. coli SW105, have been constructed for this purpose [110$112]$. A defective $\lambda$ prophage (mini- $\lambda$ ) is inserted into the $E$. coli genome and encodes heat-shock inducible genes that make recombineering possible. Linear DNA (PCR product, oligonucleotide, etc.,) with sufficient homology in the $5^{\prime}$ and $3^{\prime}$ ends to a target DNA molecule already present in the bacteria (plasmid, BAC, or the bacterial genome itself) can be electroporated into heat-shocked and electrocompetent bacteria cells and undergoes homologous recombination with the target molecule. Utilizing recombineering techniques, site-specific mutations can be introduced anywhere in the viral genome. All mutagenesis steps can be strictly controlled and analyzed in E. coli, and the manipulated viral genome can be stably maintained in the E. coli.

The entire FeHV-1 genome was previously cloned as a BAC in our lab, from which the complete FeHV-1 genomic sequence was derived [14]. The BAC-cloned virus was characterized in vitro and in vivo. Prior to defining the in vitro growth characteristics of the BAC-cloned virus, the BAC cassette was excised from the cloned virus genome. We then performed plaque size analysis and constructed multiplestep growth curves for the FeHV-1 $\triangle \mathrm{BAC}$ and its C-27 parent strain. Plaques produced by the C-27 strain and FeHV$1 \triangle \mathrm{BAC}$ virus were morphologically undistinguishable from each other. The mean plaque diameter of the FeHV-1 $\triangle B A C$ virus was $101.05 \%$ of that of the C-27 parent strain and not significantly different. Multistep growth curve analysis showed that they can grow to a similar titer.

To investigate possible attenuation resulting from $\mathrm{BAC}$ cloning itself, a preliminary challenge experiment was carried out, using four specific-pathogen-free (SPF) cats. Two cats were inoculated intranasally with the FeHV-1 $\Delta$ BAC virus, and the other two cats were inoculated intranasally with either the C-27 strain or cell culture medium. The main conclusion from the in vivo experiment was that the BAC clone-derived virus behaved very similarly to its C-27 parent strain both in vitro and in vivo, making it an excellent starting platform for introducing mutations aimed at deleting virulence-inducing genes from the FeHV-1 genome [14].

\section{Mucosal Vaccination and Epitope-Based Vaccines}

A major goal of strategies to immunize against alphaherpesvirus infections is to prevent primary infection, which would in turn prevent primary disease and the establishment of latency and subsequent latency reactivation. Latency reactivation has been shown to occur frequently, leading to virus shedding, which is asymptomatic in most cases. Natural infection provides protection against reinfection of primary mucosal replication sites for a certain period of time. This provides a rationale for the development of immunization strategies at the mucosal level.

Innate immune responses are the first to develop after natural infection. The recognition of alphaherpesvirus components by toll-like receptors is an important mechanism for induction of these responses. HSV and its components bind to TLR 2, 3, 7, and 9. Synthetic agonists have been designed to transiently activate the innate immune response [113].

In human medicine, the majority of the efforts to develop immunization strategies against herpesvirus infections have been focused on the prevention of genital herpes. However, it is also well recognized that ocular HSV-1 infection is a leading worldwide cause of herpetic keratitis, which can lead to corneal blindness. Like is the case for FeHV-1, the most severe ocular HSV-1 infections are the result of repeated reactivation events. It is clear that mucosal delivery is the best approach to generate secretory immunity and cytotoxic Tcell responses at mucosal sites.

Long-term efforts to immunize against human alphaherpesvirus infections have included subunit vaccines, modified-live vaccines, replication-defective vaccines, viral vector vaccines, and naked DNA vaccines. Despite these efforts, there are no licensed vaccines available.

One of the current approaches to mucosal immunization focuses on the development of a multiepitope self-adjuvant lipopeptide vaccine. A recent overview of this approach by the group that has pioneered it highlights its promise, but also the hurdles that still have to be overcome [114]. They point out that, based upon recent trials, the induction of neutralizing antibodies is not sufficient for protection. Implied from these results is that the induction of appropriate and adequate protective T-cell responses is a crucial part of the development of protective immunity. The essential components of a protective immune response can be the prevention of primary infection or the prevention or reduction of reactivation events. It is clear from their work, and that of others, that individuals that are latently infected with HSV, have frequent reactivation events associated with virus shedding. This reactivation is not associated with clinical signs in most individuals, which are therefore termed asymptomatic individuals. In contrast, the term symptomatic individuals is used for those in which frequent reactivation is associated with clinical signs. An important element of the strategy is to characterize the unique T-cell repertoire in HSV-positive individuals that do not suffer from frequent symptomatic reactivation. It has been determined that a set of human $\mathrm{T}$ cell epitopes from HSV-1 gB and gD are strongly recognized by $\mathrm{T}$-cells from asymptomatic individuals, but not by $\mathrm{T}$ cells from symptomatic individuals. In contrast, another nonoverlapping set of $\mathrm{gB}$ and $\mathrm{gD}$ epitopes is recognized by symptomatic individuals. The results of recent immunization of asymptomatic HLA transgenic rabbits showed that immunization with asymptomatic CD8+ epitopes from HSV-1 gD induced strong CD8+ immune responses and reduced HSV-1 shedding and tears and corneal lesions following ocular challenge virus administration. 
The authors emphasize repeatedly that the following five existing hurdles need to be overcome: (1) reasons for suboptimal immunity resulting from natural infection, (2) optimal effector mechanisms for protective immunity against the acute and latent phases of the disease, (3) knowledge about immunoevasive strategies, (4) distinction between protective versus pathogenic antigens, and (5) design of a an appropriate vaccine delivery system. They recognize that candidate vaccines need to be tested in relevant animal models if they cannot be directly evaluated in the natural host. An already existing human HLA transgenic rabbit model and the development of a similar guinea pig model are crucial tools in this respect.

\section{In Vitro Approaches to Molecular Pathogenesis}

Ocular infection with FeHV-1 results from viral exposure of conjunctival and corneal tissue. Since corneal lesions are an important disease manifestation, both during both the acute phase and as a result of reactivation, finding an effective therapy against development of ocular disease has high priority. Sandmeyer et al. [115] have reported the development of primary corneal cell culture system, which is useful for in vitro pathogenesis of ocular disease and also for the testing of potential antivirals [116]. Using this system they showed that IFN- $\alpha$ was not toxic to ocular cells and had a limited effect of virus production in FeHV-1-infected corneal cells. They speculated that a combination of IFN- $\alpha$ and other antivirals may act synergistically [117].

Pathogenesis studies of FeHV-1 have almost exclusively been done on live animals. Since the tracheal mucosa is an important replication site of FeHV-1, tracheal organ cultures are a good in vitro model to study viral invasiveness and local immune responses. Leeming et al. [118] established feline tracheal organ cultures and showed that these could be maintained for at least 5 days. Infection of these cultures at different multiplicities of infection (MOI), ranging from 0.1 to 100 , showed that the virus replicated extensively in these cultures and produced coalescing necrosis of tracheal epithelium and disruption of ciliary activity.

Since mucosal surfaces are the primary replication sites of FeHV-1, it is important to understand viral replication strategies and the local immune responses generated at these sites to better combat this mucosal pathogen. As indicated earlier, it is well known that systemically administered vaccines can prevent clinical signs but cannot prevent reinfection and the associated development of latency.

Quintana et al. [119] recently developed an equine respiratory epithelium cell culture system consisting of culturing dissociated primary epithelial cells at a liquid air interface. This is a meaningful in vitro system since epithelial cells not only provide a physical barrier against viral invasion, but also play a significant role in development of immunity by expressing toll-like receptors, by secreting cytokines, chemokines, and host defense peptides and by playing some role in antigen presentation. It was shown that epithelial cell cultures grown under these conditions were morphologically similar to intact airway epithelium. These cultures were also shown to be immunologically competent, but some properties were altered by in vitro culture under sterile conditions. The authors concluded that the addition of antigenic stimuli and/or immune cells could reverse this situation.

Mucosal explants have recently been shown for several herpesviruses to be an excellent system to study kinetics of viral invasion, as determined by the ability of a particular herpesvirus to get across the epithelial basement membrane. This system has been used to compare the invasiveness of different herpesviruses. It can, however, also be used for strain comparison and to study the role of individual or combinations of viral genes as determinants of viral virulence [120-123].

FeHV-1 infection of cats is an excellent natural host model to study mechanisms involved in establishment, maintenance, and reactivation of latency. As discussed above, latency is established in all cats following natural infection and is readily reactivated by a variety of natural stimuli or administration of corticosteroids.

De Regge et al. [124] reported the development of a homologous in vitro model to study the interaction of alphaherpesviruses and trigeminal ganglion neurons. The system consists of two concentric culture chambers. The inner and outer chambers are separated from one another by a silicon barrier, which is impermeable to both virus and cell culture medium. After 2-3 weeks in culture, axons from neuronal cell bodies present in the inner chamber grow through the silicon barrier into the outer chamber. Infection of these axons, either with HSV-1 or PRV, exclusively led to infection of neurons in the inner chamber and the subsequent spread of infection from these neurons to other neurons and nonneuronal cells. This system thus allows an in vivo-like infection of neuronal cells via retrograde axonal transport. It is, therefore, very useful to study mechanisms involved in latency establishment, maintenance, and reactivation. In a followup study, De Regge et al. [125] used this system to examine the role of IFN- $\alpha$, an important component of the innate immune system. The data showed that IFN- $\alpha$ was indeed able to establish latency in these cultures and that latency was maintained after its removal. LAT transcripts, a prominent feature of latency, were detected in the cultures by RT-PCR and the latent viral DNA could be reactivated by treatment with forskolin.

\section{A New Approach to Antiviral Therapy}

Ribonucleic acid interference (RNAi), initiated by chemically synthesized 21-mer or 27-mer small interfering RNAs (siRNA), is an alternative method to the use of standard antiviral therapy. Wilkes and Kania [126] have explored the potential of this method in vitro. The initial target was $\mathrm{gD}$ specific mRNA, based upon the fact that the gD glycoprotein plays an important role in viral attachment to susceptible cells and also in the induction of protective neutralizing antibody responses. Two of the six siRNAs they tested induced a significant reduction of virus replication in CRFK cells infected with FeHV-1. In a follow-up study Wilkes and 
Kania [127] selected siRNAs specific for the FeHV-1 DNA polymerase mRNA, the gD mRNA, or a combination of both. The hypothesis behind the targeting of the DNA polymerase was that more complete inhibition of viral replication would occur when an early rather than a late transcript was targeted. This proved to be the case, since the highest level of inhibition was obtained with a combination of 2 siRNAs targeting the FeHV-1 DNA polymerase transcript. Potential in vivo use of this approach is based upon the fact that siRNAs can be taken up effectively when applied to mucosal surfaces.

\section{Conclusions}

Recent expansion in our molecular knowledge of FeHV-1 will ultimately not only be of benefit to the health of domestic cats but will also contribute to our understanding of shared aspects of herpesvirus biology. FeHV-1 infection in cats also has potential, as a natural host system, to develop more effective immunization and treatment procedures against alphaherpesvirus infections in animals and humans.

\section{References}

[1] A. J. Davison, R. Eberle, B. Ehlers et al., "The order Herpesvirales," Archives of Virology, vol. 154, no. 1, pp. 171-177, 2009.

[2] N. James Maclachlan and J. Edward Dubovi, Eds., Fenner's Veterinary Virology, Academic Press Elsevier, 4th edition, 2001.

[3] R. Gaskell, S. Dawson, A. Radford, and E. Thiry, "Feline herpesvirus," Veterinary Research, vol. 38, no. 2, pp. 337-354, 2007.

[4] D. J. Maggs, "Update on pathogenesis, diagnosis, and treatment of feline herpesvirus type 1," Clinical Techniques in Small Animal Practice, vol. 20, no. 2, pp. 94-101, 2005.

[5] D. Gould, "Feline Herpesvirus-1. Ocular manifestations, diagnosis and treatment options," Journal of Feline Medicine and Surgery, vol. 13, no. 5, pp. 333-346, 2011.

[6] P. E. Pellett and B. Roizman, "The family Herpesviridae: a brief introduction," in Fields Virology, D. M. Knipe and P. M. Howley, Eds., pp. 2479-2499, Lippincott Williams \& Wilkins, Philadelphia, Pa, USA, 2007.

[7] B. Roizman, D. M. Knipe, and R. J. Whitley, "Herpes simplex viruses," in Fields Virology, D. M. Knipe and P. M. Howley, Eds., pp. 2502-2601, Lippincott Williams \& Wilkins, Philadelphia, Pa, USA, 2007.

[8] R. C. Povey, "A review of feline viral rhinotracheitis (feline herpesvirus I infection)," Comparative Immunology, Microbiology and Infectious Diseases, vol. 2, no. 2-3, pp. 373-387, 1979.

[9] T. C. Harder, M. Harder, H. Vos et al., "Characterization of phocid herpesvirus- 1 and -2 as putative alpha- and gammaherpesviruses of North American and European pinnipeds," Journal of General Virology, vol. 77, no. 1, pp. 27-35, 1996.

[10] T. C. Harder, M. Harder, R. L. De Swart, A. D. M. E. Osterhaus, and B. Liess, "Major immunogenic proteins of phocid herpes-viruses and their relationships to proteins of canine and feline herpesviruses," Veterinary Quarterly, vol. 20, no. 2, pp. 50-55, 1998.

[11] T. C. Harder and A. D. M. E. Osterhaus, "Molecular characterization and baculovirus expression of the glycoprotein B of a seal herpesvirus (phocid herpesvirus-1)," Virology, vol. 227, no. 2, pp. 343-352, 1997.
[12] P. A. Rota, R. K. Maes, and W. T. Ruyechan, "Physical characterization of the genome of feline herpesvirus-1," Virology, vol. 154, no. 1, pp. 168-179, 1986.

[13] A. Grail, D. A. Harbour, and W. Chia, "Restriction endonuclease mapping of the genome of feline herpesvirus type 1," Archives of Virology, vol. 116, no. 1-4, pp. 209-220, 1991.

[14] S. H. S. Tai, M. Niikura, H. H. Cheng, J. M. Kruger, A. G. Wise, and R. K. Maes, "Complete genomic sequence and an infectious BAC clone of feline herpesvirus-1 (FHV-1)," Virology, vol. 401, no. 2, pp. 215-227, 2010.

[15] D. Fargeaud, C. Benoit Jeannin, F. Kato, and G. Chappuis, "Biochemical study of the feline herpesvirus 1. Identification of glycoproteins by affinity," Archives of Virology, vol. 80, no. 2-3, pp. 69-82, 1984.

[16] K. Maeda, T. Horimoto, and T. Mikami, "Properties and functions of feline herpesvirus type 1 glycoproteins," Journal of Veterinary Medical Science, vol. 60, no. 8, pp. 881-888, 1998.

[17] M. P. Nasisse, J. S. Guy, M. G. Davidson, W. A. Sussman, and N. M. Fairley, "Experimental ocular herpes virus infection in the cat. Sites of virus replication, clinical features and effects of corticosteroid administration," Investigative Ophthalmology and Visual Science, vol. 30, no. 8, pp. 1758-1768, 1989.

[18] E. Thiry, D. Addie, S. Belák et al., "Feline herpesvirus infection ABCD guidelines on prevention and management," Journal of Feline Medicine and Surgery, vol. 11, no. 7, pp. 547$555,2009$.

[19] C. Hartley, "Aetiology of Corneal ulcers. Assume FHV-1 unless proven otherwise," Journal of Feline Medicine and Surgery, vol. 12, no. 1, pp. 24-35, 2010.

[20] G. C. Perng and C. Jones, "Towards an understanding of the herpes simplex virus type 1 latency-reactivation cycle," Interdisciplinary Perspectives on Infectious Diseases, vol. 2010, Article ID 262415, 18 pages, 2010.

[21] C. Jones, "Herpes simplex virus type 1 and bovine herpesvirus 1 latency," Clinical Microbiology Reviews, vol. 16, no. 1, pp. 79-95, 2003.

[22] C. Jones and S. Chowdhury, "A review of the biology of bovine herpesvirus type $1(\mathrm{BHV}-1)$, its role as a cofactor in the bovine respiratory disease complex and development of improved vaccines," Animal Health Research Reviews, vol. 8, no. 2, pp. 187-205, 2007.

[23] J. R. Kent, W. Kang, C. G. Miller, and N. W. Fraser, "Herpes simplex virus latency-associated transcript gene function," Journal of NeuroVirology, vol. 9, no. 3, pp. 285-290, 2003.

[24] A. Gupta, J. J. Gartner, P. Sethupathy, A. G. Hatzigeorgiou, and N. W. Fraser, "Anti-apoptotic function of a microRNA encoded by the HSV-1 latency-associated transcript," Nature, vol. 442, no. 7098, pp. 82-85, 2008.

[25] R. L. Thompson, C. M. Preston, and N. M. Sawtell, "De novo synthesis of VP16 coordinates the exit from HSV latency in vivo," PLoS Pathogens, vol. 5, no. 3, 2009.

[26] S. Jacobi, Molecular pathology of FHV-1 infection within feline cornea, conjunctiva, lacrimal gland, nictitans gland, trigeminal ganglion and ciliary ganglion [Ph.D. thesis], Michigan State University, 2008.

[27] W. M. Townsend, J. Stiles, L. Guptill-Yoran, and S. G. Krohne, "Development of a reverse transcriptase-polymerase chain reaction assay to detect feline herpesvirus-1 latency-associated transcripts in the trigeminal ganglia and corneas of cats that did not have clinical signs of ocular disease," American Journal of Veterinary Research, vol. 65, no. 3, pp. 314-319, 2004. 
[28] T. M. Ellis, "Feline respiratory virus carriers in clinically healthy cats," Australian Veterinary Journal, vol. 57, no. 3, pp. 115-118, 1981.

[29] R. M. Gaskell and R. C. Povey, "Experimental induction of feline viral rhinotracheitis virus re-excretion in FVRrecovered cats," Veterinary Record, vol. 100, no. 7, pp. 128$133,1977$.

[30] R. M. Gaskell and R. C. Povey, "Transmission of feline viral rhinotracheitis," Veterinary Record, vol. 111, no. 16, pp. 359362, 1982.

[31] R. M. Gaskell and R. C. Povey, "Reexcretion of feline viral rhinotracheitis virus following corticosteroid treatment," Veterinary Record, vol. 93, no. 7, pp. 204-205, 1973.

[32] J. Stiles, "Feline herpesvirus," Veterinary Clinics of North America, vol. 30, no. 5, pp. 1001-1014, 2000.

[33] A. Vögtlin, C. Fraefel, S. Albini et al., "Quantification of feline herpesvirus 1 DNA in ocular fluid samples of clinically diseased cats by real-time TaqMan PCR," Journal of Clinical Microbiology, vol. 40, no. 2, pp. 519-523, 2002.

[34] D. A. Dawson, J. Carman, J. Collins, S. Hill, and M. R. Lappin, "Enzyme-linked immunosorbent assay for detection of feline herpesvirus $1 \mathrm{IgG}$ in serum, aqueous humor, and cerebrospinal fluid," Journal of Veterinary Diagnostic Investigation, vol. 10, no. 4, pp. 315-319, 1998.

[35] R. Snoeck, "Antiviral therapy of herpes simplex," International Journal of Antimicrobial Agents, vol. 16, no. 2, pp. 157$159,2000$.

[36] M. P. Nasisse, D. C. Dorman, K. C. Jamison, B. J. Weigler, E. C. Hawkins, and J. B. Stevens, "Effects of valacyclovir in cats infected with feline herpesvirus 1," American Journal of Veterinary Research, vol. 58, no. 10, pp. 1141-1144, 1997.

[37] J. G. Owens, M. P. Nasisse, S. M. Tadepalli, and D. C. Dorman, "Pharmacokinetics of acyclovir in the cat," Journal of Veterinary Pharmacology and Therapeutics, vol. 19, no. 6, pp. 488-490, 1996.

[38] J. P. Fontenelle, C. C. Powell, J. K. Veir, S. V. Radecki, and M. R. Lappin, "Effect of topical ophthalmic application of cidofovir on experimentally induced primary ocular feline herpesvirus-1 infection in cats," American Journal of Veterinary Research, vol. 69, no. 2, pp. 289-293, 2008.

[39] R. Malik, N. S. Lessels, S. Webb et al., "Treatment of feline herpesvirus- 1 associated disease in cats with famciclovir and related drugs," Journal of Feline Medicine and Surgery, vol. 11, no. 1 , pp. 40-48, 2009.

[40] D. J. Maggs, M. P. Nasisse, and P. H. Kass, "Efficacy of oral supplementation with L-lysine in cats latently infected with feline herpesvirus," American Journal of Veterinary Research, vol. 64 , no. 1 , pp. 37-42, 2003.

[41] D. J. Maggs, B. K. Collins, J. G. Thorne, and M. P. Nasisse, "Effects of L-lysine and L-arginine on in vitro replication of feline herpesvirus type-1," American Journal of Veterinary Research, vol. 61, no. 12, pp. 1474-1478, 2000.

[42] J. Stiles, W. M. Townsend, Q. R. Rogers, and S. G. Krohne, "Effect of oral administration of L-lysine on conjunctivitis caused by feline herpesvirus in cats," American Journal of Veterinary Research, vol. 63, no. 1, pp. 99-103, 2002.

[43] S. L. Beaumont, D. J. Maggs, and H. E. Clarke, "Effects of bovine lactoferrin on in vitro replication of feline herpesvirus," Veterinary Ophthalmology, vol. 6, no. 3, pp. 245250, 2003.

[44] R. M. Gaskell and R. C. Povey, "Experimental induction of feline viral rhinotracheitis virus re-excretion in FVRrecovered cats," Veterinary Record, vol. 100, no. 7, pp. 128$133,1977$.
[45] T. E. Walton and J. H. Gillespie, "Feline viruses. VII. Immunity to the feline herpesvirus in kittens inoculated experimentally by the aerosol method," The Cornell Veterinarian, vol. 60, no. 2, pp. 232-239, 1970.

[46] R. M. Gaskell and R. C. Povey, "The dose response of cats to experimental infection with feline viral rhinotracheitis virus," Journal of Comparative Pathology, vol. 89, no. 2, pp. 179-191, 1979.

[47] M. R. Lappin, R. W. Sebring, M. Porter, S. J. Radecki, and J. Veir, "Effects of a single dose of an intranasal feline herpesvirus 1, calicivirus, and panleukopenia vaccine on clinical signs and virus shedding after challenge with virulent feline herpesvirus 1," Journal of Feline Medicine and Surgery, vol. 8, no. 3, pp. 158-163, 2006.

[48] R. M. Gaskell and R. C. Povey, "Transmission of feline viral rhinotracheitis," Veterinary Record, vol. 111, no. 16, pp. 359$362,1982$.

[49] S. Dawson, K. Willoughby, R. M. Gaskell, G. Wood, and W. S. Chalmers, "A field trial to assess the effect of vaccination against feline herpesvirus, feline calicivirus and feline panleucopenia virus in 6-week-old kittens," Journal of Feline Medicine and Surgery, vol. 3, no. 1, pp. 17-22, 2001.

[50] J. R. Richards, T. H. Elston, R. B. Ford et al., "The 2006 American association of feline practitioners Feline Vaccine Advisory Panel report," Journal of the American Veterinary Medical Association, vol. 229, no. 9, pp. 1405-1441, 2006.

[51] M. R. Lappin, J. Andrews, D. Simpson, and W. A. Jensen, "Use of serologic tests to predict resistance to feline herpesvirus 1, feline calicivirus, and feline parvovirus infection in cats," Journal of the American Veterinary Medical Association, vol. 220, no. 1, pp. 38-42, 2002.

[52] F. W. Scott and C. M. Geissinger, "Long-term immunity in cats vaccinated with an inactivated trivalent vaccine," American Journal of Veterinary Research, vol. 60, no. 5, pp. 652-658, 1999.

[53] M. R. Lappin, R. W. Sebring, M. Porter, S. J. Radecki, and J. Veir, "Effects of a single dose of an intranasal feline herpesvirus 1, calicivirus, and panleukopenia vaccine on clinical signs and virus shedding after challenge with virulent feline herpesvirus 1," Journal of Feline Medicine and Surgery, vol. 8, no. 3, pp. 158-163, 2006.

[54] J. M. Kruger, M. D. Sussman, and R. K. Maes, "Glycoproteins gI and gE of feline herpesvirus-1 are virulence genes: Safety and efficacy of a gI-gE- deletion mutant in the natural host," Virology, vol. 220, no. 2, pp. 299-308, 1996.

[55] M. R. Lappin, J. Veir, and J. Hawley, "Feline panleukopenia virus, feline herpesvirus-1, and feline calicivirus antibody responses in seronegative specific pathogen-free cats after a single administration of two different modified live FVRCP vaccines," Journal of Feline Medicine and Surgery, vol. 11, no. 2, pp. 159-162, 2009.

[56] R. M. Gaskell, "Upper respiratory disease in the cat (including chlamydia): control and prevention," Feline Practice, vol. 21, pp. 29-34, 1993.

[57] D. A. Harbour, P. E. Howard, and R. M. Gaskell, "Isolation of feline calicivirus and feline herpesvirus from domestic cats 1980 to 1989," Veterinary Record, vol. 128, no. 4, pp. 77-80, 1991.

[58] K. M. Tham and M. J. Studdert, "Clinical and immunological responses of cats to feline herpesvirus type 1 infection," Veterinary Record, vol. 120, no. 14, pp. 321-326, 1987.

[59] B. J. Weigler, J. S. Guy, M. P. Nasisse, S. I. Hancock, and B. Sherry, "Effect of a live attenuated intranasal vaccine on latency and shedding of feline herpesvirus 1 in domestic 
cats," Archives of Virology, vol. 142, no. 12, pp. 2389-2400, 1997.

[60] N. Yokoyama, K. Maeda, Y. Tohya et al., "Pathogenicity and vaccine efficacy of a thymidine kinase-deficient mutant of feline herpesvirus type 1 in cats," Archives of Virology, vol. 141, no. 3-4, pp. 481-494, 1996.

[61] D. Schumacher, B. Karsten Tischer, S. M. Reddy, and N. Osterrieder, "Glycoproteins e and I of marek's disease virus serotype 1 are essential for virus growth in cultured cells," Journal of Virology, vol. 75, no. 23, pp. 11307-11318, 2001.

[62] P. Balan, N. Davis-Poynter, S. Bell, H. Atkinson, H. Browne, and T. Minson, "An analysis of the in vitro and in vivo phenotypes of mutants of herpes simplex virus type 1 lacking glycoproteins gG, gE, gI or the putative gJ," Journal of General Virology, vol. 75, no. 6, pp. 1245-1258, 1994.

[63] K. S. Dingwell, C. R. Brunetti, R. L. Hendricks et al., "Herpes simplex virus glycoproteins E and I facilitate cell-to-cell spread in vivo and across junctions of cultured cells," Journal of Virology, vol. 68, no. 2, pp. 834-845, 1994.

[64] K. S. Dingwell and D. C. Johnson, "The herpes simplex virus gE-gI complex facilitates cell-to-cell spread and binds to components of cell junctions," Journal of Virology, vol. 72, no. 11, pp. 8933-8942, 1998.

[65] H. Otsuka and X. Xuan, "Construction of bovine herpesvirus-1 (BHV-1) recombinants which express pseudorabies virus (PRV) glycoproteins $\mathrm{gB}, \mathrm{gC}, \mathrm{gD}$, and $\mathrm{gE}$," Archives of Virology, vol. 141, no. 1, pp. 57-71, 1996.

[66] F. A. Zuckermann, T. C. Mettenleiter, C. Schreurs, N. Sugg, and T. Ben-Porat, "Complex between glycoproteins gI and gp63 of pseudorabies virus: its effect on virus replication," Journal of Virology, vol. 62, no. 12, pp. 4622-4626, 1988.

[67] R. J. Frink, R. Eisenberg, G. Cohen, and E. K. Wagner, "Detailed analysis of the portion of the herpes simplex virus type 1 genome encoding glycoprotein C," Journal of Virology, vol. 45, no. 2, pp. 634-647, 1983.

[68] S. Mallory, M. Sommer, and A. M. Arvin, "Mutational analysis of the role of glycoprotein I in varicella-zoster virus replication and its effects on glycoprotein E conformation and trafficking," Journal of Virology, vol. 71, no. 11, pp. 82798288, 1997.

[69] S. Mallory, M. Sommer, and A. M. Arvin, "Analysis of the glycoproteins I and E of varicella-zoster virus (VZV) using deletional mutations of VZV cosmids," Journal of Infectious Diseases, vol. 178, no. 5, supplement 1, pp. S22-S26, 1998.

[70] M. D. Sussman, R. K. Maes, J. M. Kruger, S. J. Spatz, and P. J. Venta, "A feline herpesvirus- 1 recombinant with a deletion in the genes for glycoproteins $\mathrm{gI}$ and $\mathrm{gE}$ is effective as a vaccine for feline rhinotracheitis," Virology, vol. 214, no. 1, pp. 12-20, 1995.

[71] M. J. Kaashoek, F. A. C. Van Engelenburg, A. Moerman, A. L. J. Gielkens, F. A. M. Rijsewijk, and J. T. Van Oirschot, "Virulence and immunogenicity in calves of thymidine kinaseand glycoprotein E-negative bovine herpesvirus 1 mutants," Veterinary Microbiology, vol. 48, no. 1-2, pp. 143-153, 1996.

[72] K. Tsujimurai, T. Shiosei, T. Yamanakai, M. Nemotoi, T. Kondoi, and T. Matsumurai, "Equine herpesvirus type 1 mutant defective in glycoprotein $\mathrm{E}$ gene as candidate vaccine strain," The Journal of Veterinary Medical Science, vol. 71, pp. 1439-1448, 2009.

[73] J. H. Nunberg, D. K. Wright, G. E. Cole et al., "Identification of the thymidine kinase gene of feline herpesvirus: use of degenerate oligonucleotides in the polymerase chain reaction to isolate herpesvirus gene homologs," Journal of Virology, vol. 63, no. 8, pp. 3240-3249, 1989.
[74] N. Yokoyama, K. Maeda, Y. Tohya, Y. Kawaguchi, K. Fujita, and T. Mikami, "Recombinant feline herpesvirus type 1 expressing immunogenic proteins inducible virus neutralizing antibody against feline calicivirus in cats," Vaccine, vol. 14, no. 17-18, pp. 1657-1663, 1996.

[75] M. C. Frame, F. C. Purves, D. J. McGeoch, H. S. Marsden, and D. P. Leader, "Identification of the herpes simplex virus protein kinase as the product of viral gene US3," Journal of General Virology, vol. 68, part 10, pp. 2699-2704, 1987.

[76] D. J. Mcgeoch and A. J. Davison, "Alphaherpesviruses possess a gene homologous to the protein kinase gene family of eukaryotes and retroviruses," Nucleic Acids Research, vol. 14, no. 4, pp. 1765-1777, 1986.

[77] F. C. Purves, R. M. Longnecker, D. P. Leader, and B. Roizman, "Herpes simplex virus 1 protein kinase is encoded by open reading frame US3 which is not essential for virus growth in cell culture," Journal of Virology, vol. 61, no. 9, pp. 2896-2901, 1987.

[78] R. Leopardi, C. Van Sant, and B. Roizman, “The herpes simplex virus 1 protein kinase Us3 is required for protection from apoptosis induced by the virus," Proceedings of the National Academy of Sciences of the United States of America, vol. 94, no. 15, pp. 7891-7896, 1997.

[79] J. Munger, A. V. Chee, and B. Roizman, "The Us3 protein kinase blocks apoptosis induced by the d120 mutant of herpes simplex virus 1 at a premitochondrial stage," Journal of Virology, vol. 75, no. 12, pp. 5491-5497, 2001.

[80] J. Munger and B. Roizman, "The Us3 protein kinase of herpes simplex virus 1 mediates the posttranslational modification of $\mathrm{BAD}$ and prevents $\mathrm{BAD}$-induced programmed cell death in the absence of other viral proteins," Proceedings of the National Academy of Sciences of the United States of America, vol. 98, no. 18, pp. 10410-10415, 2001.

[81] P. D. Ogg, P. J. McDonell, B. J. Ryckman, C. M. Knudson, and R. J. Roller, "The HSV-1 Us3 protein kinase is sufficient to block apoptosis induced by overexpression of a variety of Bcl-2 family members," Virology, vol. 319, no. 2, pp. 212-224, 2004.

[82] A. E. Reynolds, B. J. Ryckman, J. D. Baines, Y. Zhou, L. Liang, and R. J. Roller, "UL31 and UL34 proteins of herpes simplex virus type 1 form a complex that accumulates at the nuclear rim and is required for envelopment of nucleocapsids," Journal of Virology, vol. 75, no. 18, pp. 8803-8817, 2001.

[83] A. E. Reynolds, E. G. Wills, R. J. Roller, B. J. Ryckman, and J. D. Baines, "Ultrastructural localization of the herpes simplex virus type 1 UL31, UL34, and US3 proteins suggests specific roles in primary envelopment and egress of nucleocapsids," Journal of Virology, vol. 76, no. 17, pp. 8939-8952, 2002.

[84] A. Kato, M. Tanaka, M. Yamamoto et al., "Identification of a physiological phosphorylation site of the herpes simplex virus 1 -encoded protein kinase Us3 which regulates its optimal catalytic activity in vitro and influences its function in infected cells," Journal of Virology, vol. 82, no. 13, pp. 61726189, 2008.

[85] T. Murata, F. Goshima, Y. Nishizawa et al., "Phosphorylation of cytokeratin 17 by herpes simplex virus type 2 US3 protein kinase," Microbiology and Immunology, vol. 46, no. 10, pp. 707-719, 2002.

[86] T. G. Kimman, N. de Wind, T. de Bruin, Y. de Visser, and J. Voermans, "Inactivation of glycoprotein $\mathrm{gE}$ and thymidine kinase or the US3-encoded protein kinase synergistically decreases in vivo replication of pseudorabies virus and the induction of protective immunity," Virology, vol. 205, no. 2, pp. 511-518, 1994. 
[87] B. C. Herold, D. WuDunn, N. Soltys, and P. G. Spear, "Glycoprotein $C$ of herpes simplex virus type 1 plays a principal role in the adsorption of virus to cells and in infectivity," Journal of Virology, vol. 65, no. 3, pp. 1090-1098, 1991.

[88] T. C. Mettenleiter, L. Zsak, F. Zuckermann, N. Sugg, H. Kern, and T. Ben-Porat, "Interaction of glycoprotein gIII with a cellular heparinlike substance mediates adsorption of pseudorabies virus," Journal of Virology, vol. 64, no. 1, pp. 278-286, 1990.

[89] K. Okazaki, T. Matsuzaki, Y. Sugahara et al., "BHV-1 adsorption is mediated by the interaction of glycoprotein gIII with heparinlike moiety on the cell surface," Virology, vol. 181, no. 2, pp. 666-670, 1991.

[90] N. Osterrieder, "Construction and characterization of an equine herpesvirus 1 glycoprotein C negative mutant," Virus Research, vol. 59, no. 2, pp. 165-177, 1999.

[91] R. J. Frink, R. Eisenberg, G. Cohen, and E. K. Wagner, "Detailed analysis of the portion of the herpes simplex virus type 1 genome encoding glycoprotein C," Journal of Virology, vol. 45, no. 2, pp. 634-647, 1983.

[92] J. Lubinski, L. Wang, D. Mastellos, A. Sahu, J. D. Lambris, and H. M. Friedman, "In vivo role of complement-interacting domains of herpes simplex virus type $1 \mathrm{gC}$," Journal of Experimental Medicine, vol. 190, no. 11, pp. 1637-1646, 1999.

[93] L. F. Fries, H. M. Friedman, and G. H. Cohen, "Glycoprotein $\mathrm{C}$ of herpes simplex virus 1 is an inhibitor of the complement cascade," Journal of Immunology, vol. 137, no. 5, pp. 16361641, 1986.

[94] K. Maeda, N. Yokoyama, K. Fujita, M. Maejima, and T. Mikami, "Heparin-binding activity of feline herpesvirus type 1 glycoproteins," Virus Research, vol. 52, no. 2, pp. 169-176, 1997.

[95] M. J. Willemse, W. S. K. Chalmers, A. M. Cronenberg, R. Pfundt, I. G. L. Strijdveen, and P. J. A. Sondermeijer, "The gene downstream of the $\mathrm{gC}$ homologue in feline herpes virus type 1 is involved in the expression of virulence," Journal of General Virology, vol. 75, no. 11, pp. 3107-3116, 1994.

[96] K. Maeda, N. Yokoyama, K. Fujita, and T. Mikami, "Identification and characterization of the feline herpesvirus type 1 glycoprotein C gene," Virus Genes, vol. 14, no. 2, pp. 105-109, 1997.

[97] K. Maeda, N. Yokoyama, K. Fujita, M. Maejima, and T. Mikami, "Heparin-binding activity of feline herpesvirus type 1 glycoproteins," Virus Research, vol. 52, no. 2, pp. 169-176, 1997.

[98] G. R. van de Walle, K. W. Jarosinski, and N. Osterrieder, "Alphaherpesviruses and chemokines: pas de deux not yet brought to perfection," Journal of Virology, vol. 82, no. 13, pp. 6090-6097, 2008.

[99] G. R. van de Walle, M. L. May, W. Sukhumavasi, J. Von Einem, and N. Osterrieder, "Herpesvirus chemokine-binding glycoprotein $\mathrm{G}$ ( $\mathrm{gG}$ ) efficiently inhibits neutrophil chemotaxis in vitro and in vivo," Journal of Immunology, vol. 179, no. 6, pp. 4161-4169, 2007.

[100] N. Thormann, G. R. van de Walle, W. Azab, and N. Osterrieder, "The role of secreted glycoprotein G of equine herpesvirus type 1 and type 4 (EHV-1 and EHV-4) in immune modulation and virulence," Virus Research on line, vol. 169, no. 1, pp. 203-211, 2012.

[101] B. Costes, M. Thirion, B. Dewals et al., "Felid herpesvirus 1 glycoprotein $\mathrm{G}$ is a structural protein that mediates the binding of chemokines on the viral envelope," Microbes and Infection, vol. 8, no. 11, pp. 2657-2667, 2006.
[102] T. G. Kimman, N. De Wind, N. Oei-Lie, J. M. A. Pol, A. J. M. Berns, and A. L. J. Gielkens, "Contribution of single genes within the unique short region of Aujeszky's disease virus (suid herpesvirus type 1) to virulence, pathogenesis and immunogenicity," Journal of General Virology, vol. 73, no. 2, pp. 243-251, 1992.

[103] J. M. Devlin, G. F. Browning, C. A. Hartley et al., "Glycoprotein $\mathrm{G}$ is a virulence factor in infectious laryngotracheitis virus," Journal of General Virology, vol. 87, no. 10, pp. 28392847, 2006.

[104] J. M. Devlin, G. F. Browning, C. A. Hartley, and J. R. Gilkerson, "Glycoprotein G deficient infectious laryngotracheitis virus is a candidate attenuated vaccine," Vaccine, vol. 25, no. 18, pp. 3561-3566, 2007.

[105] J. M. Devlin, A. Viejo-Borbolla, G. F. Browning et al., "Evaluation of immunological responses to a glycoprotein G deficient candidate vaccine strain of infectious laryngotracheitis virus," Vaccine, vol. 28, no. 5, pp. 1325-1332, 2010.

[106] M. C. Verweij, A. D. Lipińska, D. Koppers-Lalic et al., "Structural and functional analysis of the TAP-inhibiting UL49.5 proteins of varicelloviruses," Molecular Immunology, vol. 48, pp. 2038-2051, 2011.

[107] H. Wei, Y. Wang, and S. I. Chowdhury, "Bovine herpesvirus type 1 (BHV-1) U(L) 49.5 luminal domain residues 30 to 32 are critical for MHC-I down-regulation in virus-infected cells," PLoS ONE, vol. 6, no. 10, Article ID e25742, 2011.

[108] H. Wei, J. He, D. B. Paulsen, and S. I. Chowdhury, "Bovine herpesvirus type 1 (BHV-1)mutant lacking UL 49.5 luminal domain residues $30-32$ and cytoplasmic tail residues 80 96 induces more rapid onset of virus neutralizing antibody response and cellular immune responses in calves than the wild-type strain Cooper," Veterinary Immunology and Immunopathology, vol. 147, pp. 223-229, 2012.

[109] H. Shizuya, B. Birren, U. J. Kim et al., "Cloning and stable maintenance of 300-kilobase-pair fragments of human DNA in Escherichia coli using an F-factor-based vector," Proceedings of the National Academy of Sciences of the United States of America, vol. 89, no. 18, pp. 8794-8797, 1992.

[110] E. C. Lee, D. Yu, J. Martinez de Velasco et al., "A highly efficient Escherichia coli-based chromosome engineering system adapted for recombinogenic targeting and subcloning of BAC DNA," Genomics, vol. 73, no. 1, pp. 56-65, 2001.

[111] S. Warming, N. Costantino, D. L. Court, N. A. Jenkins, and N. G. Copeland, "Simple and highly efficient BAC recombineering using galK selection," Nucleic Acids Research, vol. 33, no. 4, p. e36, 2005.

[112] D. Yu, H. M. Ellis, E. C. Lee, N. A. Jenkins, N. G. Copeland, and D. L. Court, "An efficient recombination system for chromosome engineering in Escherichia coli," Proceedings of the National Academy of Sciences of the United States of America, vol. 97, no. 11, pp. 5978-5983, 2000.

[113] C. L. McGowin and R. B. Pyles, "Mucosal treatments for herpes simplex virus: insights on targeted immunoprophylaxis and therapy," Future Microbiology, vol. 5, no. 1, pp. 15-22, 2010.

[114] G. Dasgupta, A. B. Nesburn, S. L. Wechsler, and L. BenMohamed, "Editorial: developing an asymptomatic mucosal herpes vaccine: the present and the future," Future Microbiology, vol. 5, no. 1, pp. 1-4, 2010.

[115] L. S. Sandmeyer, C. B. Keller, and D. Bienzle, "Culture of feline corneal epithelial cells and infection with feline herpesvirus-1 as an investigative tool," American Journal of Veterinary Research, vol. 66, no. 2, pp. 205-209, 2005. 
[116] L. S. Sandmeyer, C. B. Keller, and D. Bienzle, "Effects of cidofovir on cell death and replication of feline herpesvirus-1 in cultured feline corneal epithelial cells," American Journal of Veterinary Research, vol. 66, no. 2, pp. 217-222, 2005.

[117] L. S. Sandmeyer, C. B. Keller, and D. Bienzle, "Effects of interferon- $\alpha$ on cytopathic changes and titers for feline herpesvirus-1 in primary cultures of feline corneal epithelial cells," American Journal of Veterinary Research, vol. 66, no. 2, pp. 210-216, 2005.

[118] G. Leeming, M. L. Meli, P. Cripps et al., "Tracheal organ cultures as a useful tool to study Felid herpesvirus 1 infection in respiratory epithelium," Journal of Virological Methods, vol. 138, no. 1-2, pp. 191-195, 2006.

[119] A. M. Quintana, G. A. Landolt, K. M. Annis, and G. S. Hussey, "Immunological characterization of the equine airway epithelium and of a primary equine airway epithelial cell culture model," Veterinary Immunology and Immunopathology, vol. 140, no. 3-4, pp. 226-236, 2011.

[120] A. Vandekerckhove, S. Glorieux, W. V. D. Broeck, A. Gryspeerdt, K. M. van der Meulen, and H. J. Nauwynck, "In vitro culture of equine respiratory mucosa explants," Veterinary Journal, vol. 181, no. 3, pp. 280-287, 2009.

[121] S. Glorieux, W. Van den Broeck, K. M. van der Meulen, K. Van Reeth, H. W. Favoreel, and H. J. Nauwynck, "In vitro culture of porcine respiratory nasal mucosa explants for studying the interaction of porcine viruses with the respiratory tract," Journal of Virological Methods, vol. 142, no. 1-2, pp. 105-112, 2007.

[122] S. Glorieux, W. Van den Broeck, K. M. van der Meulen, K. Van Reeth, H. W. Favoreel, and H. J. Nauwynck, "In vitro culture of porcine respiratory nasal mucosa explants for studying the interaction of porcine viruses with the respiratory tract," Journal of Virological Methods, vol. 142, no. 1-2, pp. 105-112, 2007.

[123] L. Steukers, S. Glorieux, A. P. Vandekerckhove, H. W. Favoreel, and H. J. Nauwynck, "Diverse microbial interactions with the basement membrane barrier," Trends in Microbiology, vol. 20, pp. 147-155, 2012.

[124] N. De Regge, H. W. Favoreel, K. Geenen, and H. J. Nauwynck, "A homologous in vitro model to study interactions between alphaherpesviruses and trigeminal ganglion neurons," Veterinary Microbiology, vol. 113, no. 3-4, pp. 251-255, 2006.

[125] N. De Regge, N. Van Opdenbosch, H. J. Nauwynck, S. Efstathiou, and H. W. Favoreel, "Interferon alpha induces establishment of alphaherpesvirus latency in sensory neurons in vitro," PLoS ONE, vol. 5, no. 9, Article ID e13076, 2010.

[126] R. P. Wilkes and S. A. Kania, "Use of interfering RNAs targeted against feline herpesvirus 1 glycoprotein D for inhibition of feline herpesvirus 1 infection of feline kidney cells," American Journal of Veterinary Research, vol. 70, no. 8, pp. 1018-1025, 2009.

[127] R. P. Wilkes and S. A. Kania, "Evaluation of the effects of small interfering RNAs on in vitro replication of feline herpesvirus-1," American Journal of Veterinary Research, vol. 71, no. 6, pp. 655-663, 2010. 

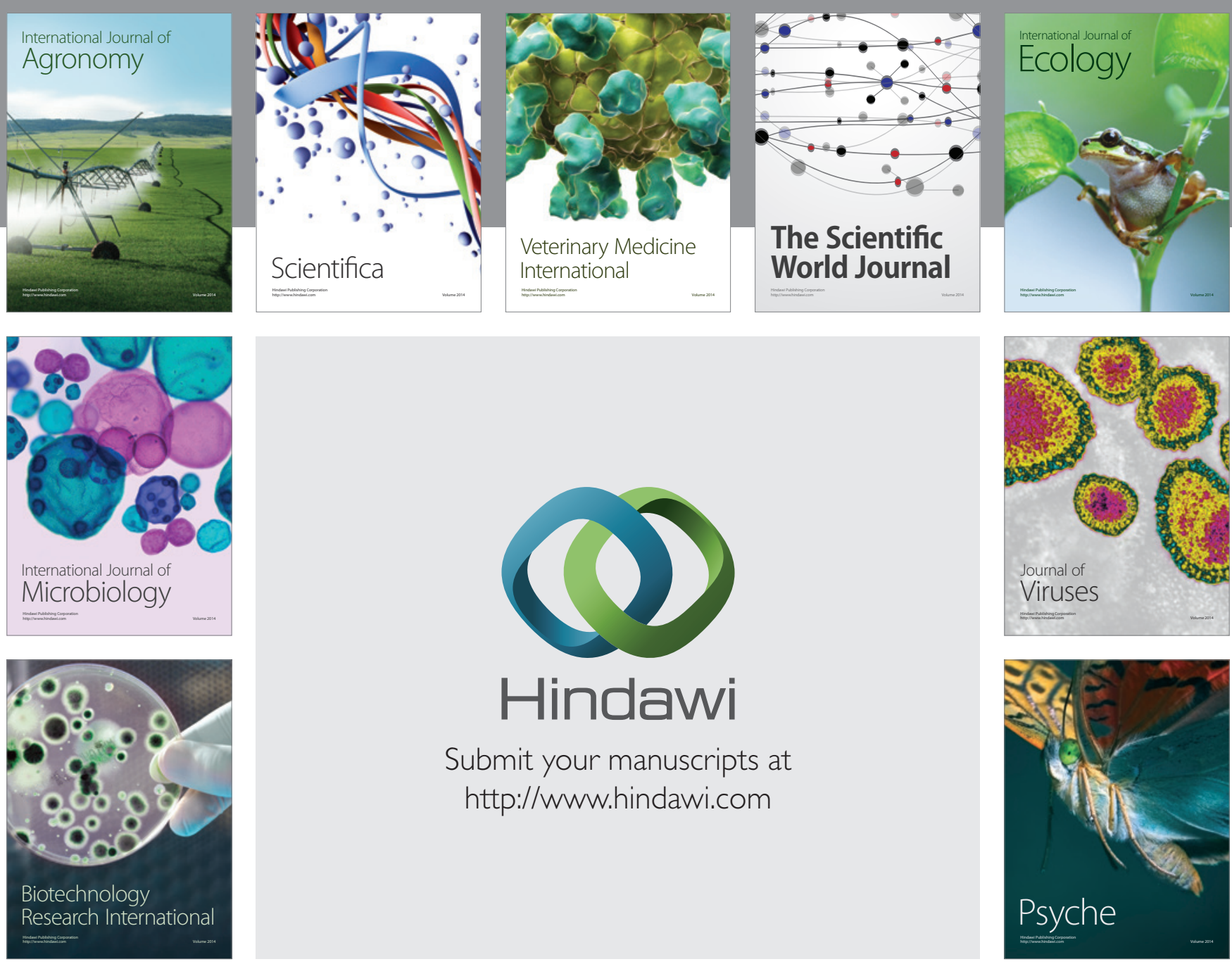

Submit your manuscripts at http://www.hindawi.com
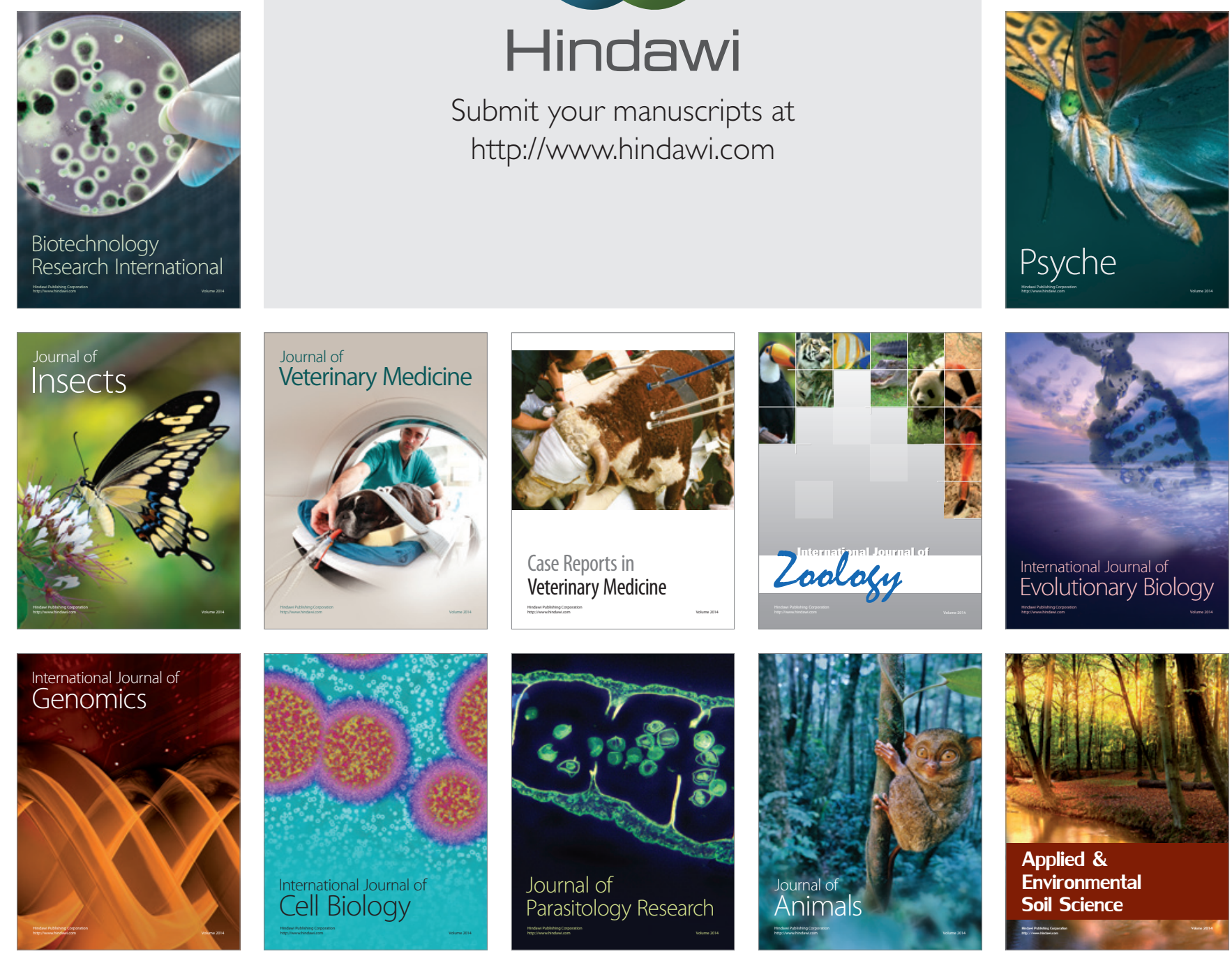